\title{
O "Estado" da Educação na "Folha" de Jornal: corno os Jornais de Grande Circulação Abordam a Questão Educacional*
}

\section{Belarmino Cesar Guimarães da Costa \\ Universidade Metodista de Piracicaba (Unimep)}

\begin{abstract}
A lógica da imprensa no capitalismo é exatamente a de misturar coisas, de desorganizar qualquer estruturação racional da realidade, e jogar ao leitor o mundo como um amontoado de fatos desconexos e sem nenhuma lógica interna — Ciro Marcondes Filho
\end{abstract}

Na sociedade industrial, os mass media produzem, excluem e transformam aspectos da realidade. Os critérios de noticiabilidade dos jornais se pautam pelo sensacionalismo, dando destaque a fatos impactuais e extraordinários, que provoquem reações imediatas nos receptores. A fragmentação e descontextualização são características da produção da notícia, enquanto mercadoria. A educação não se prende ao factual e, por isto, não adquire status de notícia e deixa de ser potencialmente problematizada. Isto ficou evidente na tramitação da LDB e na publicação de notícias sobre educação nos jornais Folha de S. Paulo e O Estado de S. Paulo, durante o impeachment do governo Collor de Mello.

\footnotetext{
*Trabalho inserido na pesquisa "O potencial pedagógico da Teoria Critica: análise de uma teoria da pedagogia radical", sob orientação do Prof. Bruno Pucci, e com financiamento do CNPq. Desde 1991, pesquisadores com formação em comunicação social, filosofia, pedagogia, história e psicologia se reúnem na Universidade Federal de São Carlos (UFSCar), para analisar as contribuições da Escola de Frankfurt, sobretudo as abordagens relativas à indústria cultural e suas críticas à cultura de massa e aos efeitos estéticos da presença dos mass media na vida contemporânea. O trabalho faz parte também da dissertação de mestrado de mesmo nome, defendida em dezembro de 1993 na referida universidade.
} 


\section{"Folha" e "O Estado": imprensa liberal}

Este trabalho analisa a abordagem dos jornais Folha de S. Paulo e $O$ Estado de $S$. Paulo para a questão educacional, durante a primeira etapa do impeachment do governo Collor de Mello, quando a Lei de Diretrizes e Bases da Educação (LDB) tramitava em regime de urgência no Congresso Nacional, sem que provocasse interesse jornalístico. A hipótese central da pesquisa leva em conta que na definição dos critérios de noticiabilidade dos jornais, que se fundamenta no sensacionalismo, a educação deixa de ser objeto preferencial de pauta, já que sua dinâmica não se reduz ao factual. Através deste estudo de caso, evidencia-se que na sociedade industrial os meios de comunicação excluem, montam e transformam aspectos da realidade, dando ênfase ao extraordinário, incomum, como prática de mercantilização da "notícia".

Cabe esclarecer que a pesquisa não compara a Folha e $O$ Estado de S. Paulo, tendo em vista investigar o espaço quantitativo dado aos temas educacionais. Mas, através destes jornais de cobertura nacional, busca analisar a tendência do jornalismo pelos fatos chocantes e como a realidade é simulada nas notícias com forte apelo emocional, cujo interesse se desloca do socialmente relevante à reação que provocam.

Esta prática torna suplementar as editorias de Educação, Ciência e Tecnologia e, cada vez rnais, reduz e banaliza os suplementos de Cultura. Como estratégia de venda, as rotativas dos jornais imprimem no mesmo ritmo das mensagens rápidas, superficiais, das fotos marcantes e dos títulos impactuais. A mercantilização da notícia, a segmentação de público, a valorização do contingencial, em síntese, representam o arrefecimento do jornalismo investigativo e afeta a credibilidade da imprensa.

Entretanto, não se pode admitir que ao constatar que a educação contradita esta concepção de notícia, que confunde interesse jornalístico com o extraordinário, de imediato também se exclua da imprensa o papel de ter na sociedade moderna, conforme Kotscho (1989, p.34), a função de fiscalizar os poderes públicos, enquanto instrumento de resistência 
democrática, contra as violações dos direitos humanos e a qualquer governo de exceção.

É importante enfatizar que no interior da sociedade civil há tensões e contradições. Se a atividade do jornalismo sob o Estado liberal comporta a idéia de hegemonia, de reprodução simbólica e de reforço do controle social, por outro lado, a decodificação da notícia, sua produção e a seleção dos fatos não eliminam a subjetividade, a dimensão crítica e a possibilidade do receptor perceber as contradições entre as informações e as suas experiências.

Este estudo considera as publicações do período de $1^{\circ}$ de setembro de $1992 \mathbf{a ~ 1}^{\mathbf{0}}$ de dezembro de 1992 (184 edições no total — "Estado" e "Folha" juntos —, em 92 dias de pesquisa), tendo em vista apenas o conteúdo de fechamento diário, com exceção das cartas de leitores e das matérias de articulistas. A razão deste procedimento está na vinculação entre o cotidiano registrado pelos jornais e a educação enquanto "fonte de notícia".

\section{A educação "ausente" das páginas do jornal}

Marcondes Filho (1989, p.12-13) faz duas observações relevantes para a comprovação da hipótese de que a educação não desperta, diante dos critérios de noticiabilidadee de definição de pauta, grande interesse editorial:

A primeira refere-se ao caráter ideológico de que a imprensa, ao promover um "ato de seleção e de exclusão" de fatos, reproduz parcialmente a realidade. A sonegação de informação representaria uma manipulação e um esquecimento do que pode ser indesejável;

A outra observação resume-se na idéia corrente de que notícia no jornalismo é a busca permanente do novo, do diferente, do extraordinário.

A "ausência" de reportagens, manchetes, artigos assinados, editoriais, constata que a educação não é valorizada pela imprensa, proporcionalmente em relação a temas econômicos, políticos e esportivos, por exemplo.

Cabe assinalar a opinião de Ernest Shaw (In: Wolf, p. 128) quando trata da influência dos meios de comunicação sobre o que o público deve 
saber ou ignorar: "as pessoas têm tendências para incluir ou excluir dos seus próprios conhecimentos aquilo que os mass media incluem ou excluem do seu próprio conteúdo".

Os assuntos veiculados influenciam nas conversações interpessoais e na tematização de problemas nos vários agenciamentos sociais. Diante da ausência de informações, cabe uma postura intelectual de recuperar, através da crítica imánente, ou seja, na própria lógica da estruturação da notícia, as dimensões veladas da realidade. Os meios de comunicação, com a transnacionalização do capital e a globalização da cultura, exercem hoje papel de "intelectual orgânico" das classes dirigentes, em escala mundial. Eles têm a propriedade de exercer controle social quando omitem fatos, simulam versões da realidade e manipulam informações de interesse público

LEI DE DIRETRIZES E BASES

Importância para a educação brasileira

Romanelli (1989, p.169-170) traça o histórico entre o espírito de democratização do País com a nova Constituição de 1946 e o processo para a aprovação, depois de 13 anos (1948-1961), da primeira LDB.

Naquela época, em função do incipiente processo de substituição de importações, iniciado por volta dos anos 30, a questão do ensino propedêutico e profissionalizante, tendo como subjacente a formação de mão-de-obra, provocava calorosas discussões, emendas e substitutivos.

A primeira $\mathrm{LDB}^{1}$ representou um período fecundo de luta ideológica onde, além do dualismo entre ensino de formação (para as elites) e

\footnotetext{
${ }^{1}$ A primeira LDB foi promulgada em 20 de dezembro de 1961 (Lei n $\left.{ }^{\circ} 4.024\right)$. A educação brasileira, durante $o$ regime militar, sobretudo pelo que se pode depreender da Reforma do Ensino de $1^{\circ}$ e $2^{\circ}$ graus (Lei ${ }^{\circ} 5.692$, de II de agosto de 1971, depois reformulada pela Lei $n^{\circ} 7.044$ de 1982), esteve sob a égide da tecnocracia, cuja habilitação do aluno secundarista era voltada à sua qualificação para o trabalho.
} 
rápida aprendizagem técnica (para a classe trabalhadora), suscitou polêmicas sobre a gratuidade do ensino oficial, a obrigatoriedade do ensino religioso nas escolas e a relação entre escola particular e estatal quanto à abrangência e à competência.

A LDB é uma legislação específica que normatiza os deveres do Estado no provimento de recursos para a educação, suas políticas administrativas e pedagógicas, a criação de órgãos e suas funções e a questão da liberdade de ensino. Ela revela a política educacional na sua dimensão macroestrutural e demonstra o estágio de democratização da sociedade, seu grau de dependência cultural e econômica. E capaz de identificar se a expansão do ensino ocorre num contexto conservador ou progressista, de liberdade e formação crítica dos indivíduos.

Nas universidades, quando se discutia a questão da autonomia, as decisões governamentais também se direcionavam, através de uma legislação autocrática, para a adequação do sistema educacional às necessidades de desenvolvimento econômico. Buffa (1979, p.231) observa que, no período da tecnocracia militar, "a racionalização, a eficiência e a produtividade tornam-se valores absolutos: têm validade em si e por si mesmos". Essa racionalidade representava a neutralização da ingerência ideológica e uma estrutura universitária rnais conservadora e administrativamente centralizada.

Depois de longos anos de ditadura, o Brasil redemocratiza-se sob a égide da Carta de 1988. As mudanças político-econômica e institucional mobilizam a sociedade e a nova LDB entra em tramitação no Congresso Nacional (1990).

Nos momentos decisivos para sua aprovação, a LDB mereceu da imprensa tratamento discreto, apesar das intermináveis discussões ideológicas. Ela propôs a criação do Conselho Nacional de Educação (CNE) e a descentralização político-administrativa, que permite aos estados e municípios decidirem sobre a organização da educação básica (ensinos fundamental e médio- $\mathrm{Pe} 2^{\circ}$ graus), além de sugerir o ensino religioso facultativo. 
Mesmo a formação de um Fórum Nacional em Defesa da Escola Pública, as mobilizações da sociedade civil, da Igreja, dos partidos políticos, pouco representaram para sensibilizar os jornais.

\section{O que foi publicado sobre a $L D B$}

O professor José Goldemberg, então ministro interino da Educação, no Estado, e o pró-reitor de graduação da Unesp, Antonio de Carvalho , na Folha, foram os dois únicos articulistas que trataram da tramitação da LDB, em regime de urgência, no Congresso Nacional. Em nenhum momento a LDB recebeu dos jornais uma opinião em editorial ou manchete de primeira página.

A "Folha", entretanto, publicou, no "Painel do Leitor", duas cartas com o título "Diretrizes da Educação", manifestando o inconformismo de Zilda Iokoi, pela Associação dos Docentes da USP, e de Manoel Seixas, com relação ao atraso do Congresso Nacional em votar e aprovar a LDB.

Segundo o Novo Manual de Redação da Folha (1992, p. 129), a coluna de leitores "deve publicar amostra representativa das diversas tendências de opinião apresentadas pelas cartas recebidas, dentro dos princípios de pluralismo que regem a linha editorial". O manual explica também que cabe à Direção de Redação julgar "a conveniência de uma resposta pública".

Com a "ausência" de publicação de cartas de leitores, só restam algumas hipóteses: $1^{\mathrm{a}}$ ) a LDB não motivou "respostas públicas" nem os jornais possibilitaram à sociedade o pluralismo de opiniões, em que pesem as controvérsias e os interesses entre diversos setores preocupados com sua tramitação; $2^{\mathrm{a}}$ ) a sociedade civil não se mobilizou adequadamente para "criar" fatos jornalísticos na imprensa; $3^{\mathrm{a}}$ ) a LDB não provocou momentos emocionantes para serem explorados pelos critérios de noticiabilidade.

Na posse do ministro da Educação, Murilo Hingel, a "Folha" obteve uma entrevista na qual ele fala de suas prioridades, do ensino superior e da construção de Centros de Atenção Integral à Criança (CIACs). Apenas no final o jornal pergunta sobre a LDB: o ministro se manifesta 
favorável à sua rápida tramitação. O "Estado", na posse de Hingel, registra que o presidente do Conselho de Reitores das Universidades Brasileiras (CRUB), Eduardo Coelho, está preocupado com a aprovação da LDB. Informações superficiais e que pouco esclarecem.

Se todas as matérias publicadas sobre a LDB fossem condensadas, uma página seria suficiente para dar conta do desinteresse jornalístico. Os leitores não foram informados sobre a luta ideológica e os impasses diante de assuntos controversos, como: a gestão democrática das universidades, o sistema nacional de educação, os ensinos privado e público, a liberdade religiosa, a organização da educação básica, a composição do Conselho Nacional de Educação.

Durante a tramitação do Projeto de Lei $\mathrm{n}^{\circ} 1.258 / 88$, que fixa as Diretrizes e Bases da Educação Nacional, os jornais deixaram de tematizar a mobilização da sociedade no Fórum Nacional em Defesa da Escola Pública, as discussões e os estudos das comissões temáticas da Câmara, as emendas e substitutivos do Poder Executivo. Em conseqüência, os jornais não despertaram o interesse do leitor e nem contribuíram para a mobilização da sociedade civil.

\section{INTERNACIONAL}

Se o leitor se pautasse pelos dois jornais para tomar conhecimento de projetos educacionais e políticas de ensino fora do Brasil, encontraria razões para buscar outras fontes. Neste caso, a "Folha" e o Estado forneceram pequenas notas, dificilmente ultrapassando duas colunas e sem registro fotográfico.

Pois, vejamos o que seria possível depreender da educação no exterior:

Daria para saber que a Unesco criou uma comissão de educação, ciência e cultura, que vai, segundo a "Folha", "estudar as perspectivas da educação". O jornal não esclarece a competência desse órgão internacio- 
nal, sua ação nos países a ele filiados e nem sua representatividade no Brasil. Apenas informa o nome do diretor-geral da comissão, Frederico Mayor, e a sua opinião de que "a proteção das minorias é o grande desafio do próximo século".

Merton e Lazarsfeld (1990, p.115) qualificariam este procedimento como "disfunção narcotizante". Para eles, é uma característica dos mass media se preocuparem superficialmente com os problemas sociais enquanto os indivíduos imaginariam conhecer os fatos cotidianos e não atuariam sobre eles.

O leitor do jornal O Estado de S. Paulo tomaria conhecimento da missão cubana que veio ao Brasil para intensificar intercâmbio, principalmente, na área de biotecnologia e sua aplicação na produção de medicamentos e na agricultura.

Os leitores do "Estado" seriam informados sobre o Prêmio Interamericano de Educação que a Organização dos Estados Americanos (OEA) conferiu a Paulo Freire. Anualmente, é laureado "o educador que rnais se destaca no continente". O educador recebeu o prêmio pelo trabalho "alcançado em outros países como fonte de transformação educativa", bem como "ao desenvolvimento da teoria e da prática na educação de adultos e em sua alfabetização".

A escassa relação de matérias internacionais sobre educação resume-se em relatar que no Japão os estudantes teriam um sábado livre por mês ou que um garoto de 4 anos vai à universidade, na Inglaterra. Em nenhum momento escapa-se ao não-essencial, à fragmentação da informação e à exposição de fatos insólitos, caricaturais.

A única ressalva deve ser feita ao artigo "EUA vetam 'quotas raciais' em faculdade", onde a "Folha", através de seu correspondente em Washington, Lins da Silva, faz um histórico sobre o estabelecimento de "quotas" de vagas a hispânicos, negros e asiáticos, no processo de admissão de estudantes na Faculdade de Direito da Universidade da Califórnia, em Berkeley.

Durante o período investigado, não se pôde formular qualquer hipótese sobre a educação em outros países, seus projetos e planos de ensino. 
Ao publicar qualquer informação na primeira página, evidencia-se o seu destaque na edição. Dando importância ao inesperado, que causa ruptura nos acontecimentos cotidianos, e que foge do planejado, previsto, o jornal deixa de considerar a educação como objeto de pauta, e, claramente, isto se reflete nas chamadas de primeira página.

Durante o período, somente uma única edição destacou, como manchete principal do jornal, uma questão relacionada à educação. Foi quando o Ministério da Educação tomou a medida inusitada de comprar vagas em escolas particulares "para acomodar alunos de $1^{\circ}$ grau que não puderem ser absorvidos pela rede pública e cujos pais não tenham como pagar o ensino privado".

Diante do conceito de "notícia" proposto por Marcondes Filho (1989, p.12-13), que assinala seu caráter de anormalidade, a compra de vagas pelo governo em escolas pagas provoca no leitor interesse pelo incomum.

Enquanto produto que circula no mercado, a notícia atrai pelo inusitado. Diante do mercado jornalístico competitivo, a concorrência faz com que os títulos sensacionalistas, a comicidade e o trágico sejam critérios para a pauta ${ }^{2}$.

Com o processo de racionalização na construção da notícia, que valoriza o "utilitário" e o circunstancial, as leituras apressadas, as editorias de educação, ciência e tecnologia, meio ambiente e cultura, cada vez rnais ficam marginalizadas.

A primeira página reservou chamadas para a greve dos professores da rede estadual de ensino. Também enfocou, principalmente, a mobilização estudantil pelo impeachment do presidente Collor, os reajustes das mensalidades escolares e os vestibulares.

\footnotetext{
${ }^{2}$ Conjunto de assuntos cobertos pela edição do jornal ou uma série de indicações ao repórter, com o objetivo de fornecer subsídios que ele possa explorar na noticia.
} 
Mereceria análise rnais detida o interesse mercadológico dos jornais em alimentarem a própria auto-imagem. É o caso de o "Estado" publicar na primeira página a pesquisa da Fundação para o Desenvolvimento da Educação, de que é o "jornal que os estudantes preferem nas bibliotecas das escolas"; ou o da "Folha", ao informar que o seu projeto "Folha Educação", vai às escolas incentivar a leitura dos jornais.

\section{O que foi publicado sobre educação}

Foram publicadas, preferencialmente, matérias da greve de professores, a participação dos estudantes no impeachment do governo Collor, informações sobre vestibulares e o reajuste das escolas particulares.

Do ponto de vista da produção jornalística, vamos procurar explicar esse enfoque editorial e, também, analisar os artigos assinados, para detectar quais são os interlocutores da "Folha" e do "Estado" "legitimados" para opinarem sobre temas educacionais. Merton e Lazarsfeld (1990, p.110) observam que os meios de comunicação "atribuem status" às causas públicas, às pessoas, às organizações e aos movimentos sociais. Neste caso, cabe assinalar como isto ocorre com a seleção de críticos e colaboradores.

Neste item, ainda iremos tratar das matérias conceituais que abordam temas relevantes para a compreensão da problemática da educação brasileira, tais como: política educacional, metodologia de ensino e propostas de ensino-aprendizagem. Por último, uma abordagem dos editoriais para se saber quais foram os assuntos que mereceram opinião expressa da "Folha" e do "Estado".

GREVE DOS PROFESSORES

A greve na rede estadual de São Paulo foi amplamente coberta pelo "Estado" e pela "Folha". Do ponto de vista quantitativo, isto se deve ao enorme contingente de alunos (cerca de 6 milhões) e professores (por 
volta de 235 mil, no estado), além de familiares, que são mobilizados no período de paralisação.

Com respeito a hipótese de que "notícia" representa uma ruptura da linearidade dos fatos, a paralisação na rede estadual provoca na imprensa acompanhamento permanente. O Novo Manual de Redação da Folha (1992, p.34), inclusive, apresenta um verbete próprio sobre como o jornalista deve proceder na produção de notícias a respeito de movimpntn Prevista e suas negociações.

Vamos aos "fatos" sobre a greve:

A "Folha", no dia $1^{\circ}$ de setembro, publicou na "manchete interna" do caderno "Cotidiano": "Professores de SP decretam greve hoje. Seis milhões de alunos de escolas estaduais serão afetados; governo diz que não tem dinheiro para aumentar salários". Ao lado do corpo da matéria, um quadro editado onde informa que os "pais criticam a paralisação".

Antes de informar sobre a reivindicação das perdas salariais, o jornal sintetiza no título a informação que considera rnais importante no texto, antecipando ao leitor que a greve causará prejuízos aos alunos e que é ineficaz, pois o governo não tem como recuperar os índices de salário. Cabe assinalar que o próprio jornal reconhece no manual de redação $(1992$, p.168) que a maioria dos leitores "lê apenas o título da maior parte dos textos editados".

A técnica jornalística de titulação exerce influência na percepção fragmentada dos fatos, cuja síntese arbitrária de se selecionar a informação "rnais importante" como manchete direciona a leitura, propicia a formulação de preconceitos e cristaliza no particular o conhecimento da realidade. Esta prática despotencializa a objetividade que os jornais liberais a si atribuem.

A regra jornalística ${ }^{3}$ estabelece que o primeiro parágrafo deve conter, de forma concisa, as informações essenciais para a compreensão do

\footnotetext{
${ }^{3}$ Denominada lead, representa a abertura da matéria. Os textos noticiosos precisam sempre responder às clássicas perguntas: O quê? Quem? Quando? Onde? Como? e Por quê?
} 
texto. A intenção da Folha foi caracterizar o movimento de greve dos professores, desde o início, como uma paralisação política. Pois, vejamos:

Já na abertura, o jornal informa que a greve de professores irá afetar 6 milhões de estudantes, para, em seguida, indicar que ela "começa dez meses após o lançamento da 'reforma no ensino estadual', pelo governo Fleury (PMDB), e dois meses antes das eleições municipais".

De forma subliminar, a greve passa a ser relacionada a dois momentos políticos, como se ela fosse uma resposta à insatisfação dos professores pela reforma de ensino ou que representasse deliberadamente uma atitude de desestabilização do governo, no período pré-eleitoral. No segundo parágrafo, a "Folha" vincula as entidades representativas dos professores a partidos políticos. Por último, aborda especificamente a reivindicação e fala da defasagem salarial, dos índices e da impossibilidade da Secretaria da Educação aumentar salários por causa da queda de arrecadação.

No dia seguinte, a "Folha" publicou: "Greve deixa 2 milhões sem aula em São Paulo" Esta suíte ${ }^{4}$ reproduziu no título e no lead as consequiências negativas da paralisação.

Esta vinculação entre movimento grevista e uso político ficaria rnais evidente no "Estado", quando destacou a opinião do secretário da Educação, Fernando Morais, que disse "desconfiar dos propósitos do movimento ao lembrar a filiação partidária dos líderes de professores".

Apesar da troca de acusações entre o secretário da Educação e o presidente do Sindicato de Professores, o título favoreceu à legitimação da autoridade: "Educação - Professores fazem greve política, afirma secretário" (grifos nossos).

Se a maioria das pessoas resume a leitura através dos títulos, fica evidente o falseamento de informações complexas quando a greve é tida apenas como movimento político, e deixa de considerar a reposição de

\footnotetext{
${ }^{4}$ Reportagem que explora os desdobramentos de um fato noticiado na edição anterior.
} 
perdas salariais e as cláusulas sociais ou a luta do magistério pela qualidade de ensino. Somente no último parágrafo o jornal trata dos índices e da política salarial reivindicados pelos docentes.

A vinculação entre a greve e seu uso político voltaria a ser objeto de pauta, quando a "Folha" noticiou que os "Professores em greve lançam folheto eleitoral - PF apreende 1 milhão de panfletos contra Maluf na gráfica da Apeoesp; categoria mantém paralisação". Normalmente, esta prática busca diminuir a legitimidade de movimentos grevistas.

\section{MOBILIZAÇÃO ESTUDANTIL PELO IMPEACHMENT}

Em "quase todos os dias das últimas semanas do governo Collor, os estudantes fizeram passeatas nas cidades rnais importantes do País. Com as caras pintadas e irreverentes, eles se transformaram na marca registrada das manifestações pelo impeachment".

Com esta afirmação, o jornal "Estado" sintetizou aquele momento de crise político-institucional, e como os jovens acabaram representando para os mass media um símbolo de resistência da sociedade civil.

O movimento estudantil nos ajuda a esclarecer a influência educativa dos jornais em definir papéis sociais, naquilo que reforçam $o$ senso comum e uma representação estereotipada da realidade.

Durante todo o processo de impeachment, nas passeatas e manifestações de rua, as pinturas de rosto simbolizavam o protesto irreverente, a alegria descompromissada, o bom humor e a sensualidade. De forma intensa, a publicidade nos mass media explorou estes arquétipos de jovialidade. As fotos publicadas mostram o "espírito teen" do período.

Quando o presidente da República foi afastado temporariamente de suas funções até que o Congresso votasse o impeachment, os mass media, e os jornais em particular, viam com simpatia a presença da mobilização estudantil. A admissibilidade para o afastamento de Collor por 180 dias, para ser julgado por crime de responsabilidade, no Senado, 
ocorreu em setembro de 1992. Em seu lugar foi empossado o vice-presidente, Itamar Franco.

Para o senso comum, o "natural" seria o retorno às atividades acadêmicas. Entretanto, isto não ocorreu: os estudantes se mobilizaram novamente, desta vez contra o processo de privatização de empresas estatais.

Através de editorial, o "Estado" criticou a atitude de "regresso" da UNE em tentar impedir a privatização da Acesita, com apoio da Central Única dos Trabalhadores (CUT), observando que estas entidades estariam fazendo "o jogo da oligarquia" e "agravando as condições de hospitais, escolas e universidades".

Dois dias depois era publicada esta opinião de Cândido Mota no "Fórum dos Leitores" do "Estado": "O jovem Lindberg Farias, presidente da União Nacional dos Estudantes (UNE), parece aproveitar a importância que os estudantes tiveram nos últimos meses para 'meter o dedo' $\mathrm{em}$ assuntos que não lhe dizem respeito e que certamente não são do interesse de todos os estudantes. Ele deve defender é rnais dinheiro e melhor estrutura para o deficitário ensino no Brasil" (destaque nosso).

Como foi dito, os assuntos pautados pelos mass media influenciam o público na definição de temas que devem saber ou ignorar, realçar ou negligenciar. A resposta imediata dos leitores, refletindo a opinião do jornal, ratifica sua influência ideológica no plano do senso comum.

\section{VESTIBULAR}

No jornalismo há uma série de fatos que invariavelmente se retoma de ano a ano, como, por exemplo, a volta às aulas, a Páscoa, o movimento nas estradas após um feriado prolongado, o Dia de Finados.

Igualmente, no período de pré-vestibular e após a realização de provas para o ingresso nas principais instituições de ensino do País, os jornais informam sobre a compra de manual, o número de vagas, o prazo de inscrição, os cursos rnais concorridos, as provas corrigidas, a lista com a divulgação dos aprovados etc. 
O "Estado" e a "Folha" cobrem tudo relacionado com vestibular, criando inclusive cadernos especiais dirigidos aos jovens e adolescentes.

Do ponto de vista mercadológico, este interesse especial pelos exames vestibulares encontra algumas explicações. Vejamos:

$1^{\text {a) }}$ Existe uma preocupação permanente na formação de novos leitores, o que se verifica com a publicação de cadernos segmentados para os jovens ("Folhateen", na "Folha", e "Cola", no "Estado") e acompanhamento dos principais vestibulares do País.

$2^{\mathrm{a}}$ ) A inserção de publicidade de empresas que têm interesse econômico-financeiro, como escolas particulares e cursinhos;

Cabe notar que, segundo o Novo Manual de Redação da Folha (1992, p.21), "a publicidade tem prioridade na divisão do espaço do jornal". A publicação de artigos sobre vestibular atende aos interesses de ampliar a venda dos jornais em banca e aumentar o faturamento da empresa com a publicidade.

Levando em conta o segmento do seu público leitor, esses jornais são lidos por jovens com poder de compra diferenciado. $\mathrm{O}$ acesso privilegiado de informações reforça a dicotomização entre ensino propedêutico para as classes dirigentes e técnico-profissional izante para as camadas da população com menor poder aquisitivo.

Caberia um estudo à parte sobre essa dicotomização, mas basta mencionar que o acesso aos jornais propicia uma informação diferenciada, que se relaciona com o habitus cultural, cuja função se estende na "legitimação das diferenças sociais cumprida pelas diferenças culturais" (Bourdieu, 1974, p.131).

\section{REAJUSTES DAS ESCOLAS PARTICULARES}

A emergência dos acontecimentos cotidianos, a exploração do factual, a transitoriedade dos fatos e seu registro pelo aspecto emocional, que caracterizam a lógica da produção e linguagem jornalísticas, faz com 
que assuntos como o reajuste do preço das mensalidades escolares, que tem toda uma implicação de natureza histórica, seja tratado de maneira contingencial.

Um exemplo deste procedimento pode ser percebido na greve de fome feita pelos alunos da PUC do Paraná, quando se manifestaram favoráveis à redução das mensalidades, em setembro de 1992. A greve de fome poderia motivar reportagens sobre a função social do ensino particular e suas condições diferenciadas. Entretanto, a "Folha" trocou o essencial pelo registro de aspectos fortuitos. Destacou que a greve de fome dos alunos se concentrava "em frente a uma lanchonete do McDonald's", acrescentando que uma das estudantes resistia à fome, porque já foi bandeirante. Informou ainda que outro aluno já ficou sem comer quando praticava alpinismo.

Neste caso, a greve de protesto pelo alto custo das mensalidades escolares, que tem suas implicações econômicas e sociais e toda uma relação direta com a política educacional, acaba sendo banalizada ante informações que não dão conta da complexidade do problema. Isto evidencia outra característica dos mass media: a banalização dos acontecimentos sociais, pela exploração do sensacionalismo e redução da realidade ao espetacular.

Para a construção da notícia, isto se justifica, pois a sua lógica explora os elementos diferenciais dos fatos (sensacionais). Por outro lado, a notícia, enquanto mercadoria, precisa provocar uma reação de consumo diante da concorrência. Por isto, o jornal sempre se preocupa com a informação exclusiva, tomando como referência para a construção da narração dos fatos o que virtualmente pode não ser explorado por outros órgãos de comunicação.

Esta passagem da greve da PUC do Paraná revela a semiformação, no sentido dado por Adorno (1992, p.41), como uma "forma dominante de consciência atual, apesar de toda ilustração e toda informação que se difunde, e com sua ajuda". A imprensa liberal se situa no interior da indústria cultural, cuja característica se volta para o reforço da (de) formação cultural, ao fragmentar a realidade e reconstruir os fatos pelo que apresentam de superficial. 
O impasse causado pela indefinição das mensalidades nas escolas particulares sempre provoca muitas reportagens. Do ponto de vista jornalístico tem uma lógica: o litígio na justiça, a reação de pais de alunos, os protestos e as manifestações de alunos em greve, passeatas, a discussão sobre os índices e contratos, tudo isto provoca a imersão no cotidiano, na reação diante do imediato.

Os jornais pouco tratam a questão das mensalidades, enfocando, historicamente, a função social do ensino particular, a dualidade entre formação propedêutica e profissionalizante ou sobre a expansão da rede privada de ensino enquanto investimento lucrativo. Dificilmente os jornais se preocupam com questões temáticas, conceituais. Prevalece a construção dos fatos alicerçados no imediato. É a lógica intrínseca à imprensa.

\section{INTERLOCUTORES DOS JORNAIS}

Na continuação de nossa análise sobre os critérios de seleção e de exclusão de fatos pela imprensa, tendo como referência a hipótese de que educação não figura como tema preferencial de pauta, vamos agora abordar um novo aspecto: o da legitimação que os jornais atribuem aos seus interlocutores.

Para Merton e Lazarsfeld (1990, p.110), entre as muitas funções sociais dos mass media, uma pode ser caracterizada pela atribuição de status às causas públicas, às pessoas, às organizações e aos movimentos sociais. Na escolha de seus articulistas, a "Folha" e o"Estado" pouco diferem em legitimar, pelo espaço concedido, as opiniões de governantes, parlamentares e, sobretudo, dos reitores das universidades estaduais de São Paulo (USP, Unesp e Unicamp).

Na coluna "Tendências e Debates" da "Folha" e no "Espaço Aberto" do "Estado", onde são publicados artigos de colaboradores, em nenhum momento foi dado espaço para instituições não-governamentais ou para segmentos extra-universitários. Neste sentido, Kant (1985, p.104) alerta para o fato de que a verdadeira condição humana está em sair do estado de 
"menoridade", da submissão do pensamento individual ou de um povo ao poder tutelar, heterônomo. O filósofo alemão acrescenta que, através do "esclarecimento", torna-se público o uso da razão. A incorporação do pensamento kantiano, no caso da seleção e da exclusão de articulistas, dá-se no interesse de enfatizar o papel dos meios de comunicação na definição dos segmentos que, legitimamente, adquirem status de cidadania.

Basta observar que, do total de 32 artigos assinados, 11 respondiam pelos reitores das universidades paulistas: Roberto Leal Lobo e Silva Filho (USP); Carlos Vogh (Unicamp) e Paulo Milton Landin (Unesp). Como exreitor da USP e ministro da Educação (além de secretário da Ciência e Tecnologia), José Goldemberg teve publicado oito artigos. Juntos representam, aproximadamente, $60 \%$ do material coletado. Os mass media, neste caso, acabam sendo um locus de legitimação fora do espaço próprio da academia.

Não estamos diminuindo a importância destes artigos que expressam o pensamento de lideranças acadêmicas, mas novamente assinalando a exclusão de outras fontes. O pluralismo de idéias e a democracia editorial, bandeiras dos jornais liberais, ficam insustentáveis se a educação não for pensada a partir de diferentes perspectivas.

Isto confirma a omissão de informação sobre propostas, projetos comunitários de amplos setores da sociedade civil, fora do âmbito do governo e da academia, que dificilmente vêem seus representantes ocuparem espaço dedicado aos artigos assinados.

ARTIGOS RELEVANTES PARA A EDUCAÇÃO

\section{Tese da semana}

Toda segunda-feira, a "Folha" publica uma coluna sobre a defesa de teses e de dissertações no caderno "Cotidiano", informando basicamente sobre: o tema da pesquisa, o nome do pesquisador, o nome da tese, banca, nota, tempo de elaboração e a carreira acadêmica do pesquisador. 
Foram divulgados 12 trabalhos acadêmicos, sendo $50 \%$ originados em pesquisas feitas na Universidade de São Paulo (USP).

Pelo que se depreende das áreas de concentração das teses e dissertações, os leitores da "Folha" têm predileção por assuntos de psicologia e filosofia, principalmente. Estas duas áreas forarn responsáveis por sete publicações.

Talvez esteja subjacente que a psicologia e a filosofia, enquanto especulação de visões de mundo, façam o leitor compreender melhor a vida contemporânea. A crítica não se dirige aos temas enfocados, mas ao tratamento superficial, reduzindo a psicologia e a filosofia ao recente interesse editorial pela neurolingüística, publicações místicas e de auto-estímulo.

\section{Política educacional}

Para efeito de uma abordagem sobre a política educacional, vamos distribuir os assuntos de acordo com o nível de escolaridade, e saber o que foi publicado sobre o ensino básico, médio e superior.

Normalmente, quando se trata de política educacional no País, de um novo projeto pedagógico que está sendo implantado, muito pouco se fala da capacitação docente e de procedimentos metodológicos. Às vezes, a implementação do programa acaba, exclusivamente, confundindo-se com reformas físicas nos prédios escolares e na construção de novas unidades.

Com relação à política educacional voltada ao ensino básico, os jornais deram destaque para o programa do governo de construção dos Centros Integrados de Atendimento à Criança (CIACs), enfocando, particularmente, sua vinculação com o orçamento da União e a crise do setor habitacional.

O "Estado" publicou uma entrevista com o novo ministro da Educação do governo Itamar Franco, Murilo Hingel, e já no título destacou que iria haver, por parte do Ministério da Educação, uma revisão dos CIACs.

Tendo subjacente o direcionamento de qualquer entrevista, as três perguntas iniciais denotam a preocupação do jornal em privilegiar ques- 
tões sobre orçamento e o projeto de construção física dos CIACs. O "Estado" perguntou ao ministro: 1 - 0 governo vai suspender a construção dos Centros Integrados de Apoio à Criança?; 2 - Até que ponto as restrições podem comprometer o projeto?; 3 - Todos os CIACs anunciados serão construídos?

Apenas no final da entrevista, após uma série de preocupações orçamentárias, o repórter do jornal questiona se a universidade pública pode passar para a iniciativa privada e quais são as outras prioridades do Ministério da Educação. $\mathrm{O}$ box ${ }^{5}$ ao lado da entrevista informa sobre as principais propostas do governo, dentre elas, a abertura de cursos noturnos nas universidades públicas e a intenção manifestada pelo ministro Murilo Hingel em dar maior atenção ao ensino profissionalizante e ao ensino de base.

Entretanto, estas questões relevantes para a definição da política educacional são apenas pontuadas; esgotam-se em ser apenas anunciadas. A ausência de contextualização histórica, a perda da dimensão de criticidade que vai além do discurso, da retórica, caracterizam a lógica da produção da notícia. É oportuna a afirmação de Horkheimer e Adorno (1990, p. 177) quando dizem que o consumidor da indústria cultural deve se contentar com a "leitura do menu"; simbolicamente, isto representa o seu caráter (de) formador, a socialização da semicultura.

A respeito da política educacional para o ensino médio, como se pode depreender, os jornais dificilmente abordam temas conceituais que demonstrem preocupação histórica e filosófica. Novamente podemos citar as contradições entre ensino propedêutico dirigido às classes dirigentes e a formação profissionalizante, para as camadas populares, que têm implicações ideológicas essenciais para a estrutura do ensino médio, e que nunca são mencionadas.

\footnotetext{
${ }^{5}$ Pequeno texto editado em corpo diferente e em destaque, em meio a matéria rnais extensa, com a finalidade de acrescentar informações relevantes para a compreensão do assunto.
} 
Neste sentido, torna-se significativa a reportagem do "Estado" sobre a iniciativa da Secretaria de Ciência, Tecnologia e Desenvolvimento Econômico do Estado de São Paulo, em investir US\$ 70 milhões para a recuperação e a modernização de 80 escolas técnicas do $2^{o}$ grau.

Sem tratar da referida contradição, a matéria fala da reformulação curricular do ensino técnico no sentido de adequá-lo "às exigências ditadas pela modernização do setor produtivo, com a incorporação de novas tecnologias". Esta opinião do secretário de Ciência e Tecnologia, Delben Leite, suscita controvérsias e dá margem a problematizações rnais sérias quanto ao caráter reprodutivo da adaptação do sistema educacional à demanda de incorporação de mão-de-obra no setor secundário.

O texto também denota a preocupação de tratar a recuperação e a modernização do ensino técnico de $2^{\circ}$ grau apenas pela reforma dos prédios escolares ou na projeção de dados estatísticos de alunos matriculados.

Tal como para as ciências exatas, a quantificação é essencial e define no jornalismo os critérios para a estruturação da mensagem. Desta maneira, o fuzilamento de meninos de rua, em julho de 1993, no Rio de Janeiro, estimulou contingencialmente nos meios de comunicação uma série de reportagens sobre o extermínio de menores no País.

O problema de menores abandonados e a morte cotidiana e silenciosa nas grandes cidades, que não têm uma representação quantitativa aparente e nem se relacionam com o virtualmente trágico, ficam no esquecimento. Há a necessidade de qualquer acontecimento extraordinário que, de repente, registre vários feridos e mortos para os meios de comunicação explorarem até a exaustão. A catarse perdura alguns dias, até outro acontecimento trágico tomar conta dos noticiários.

Quanto ao ensino universitário, os jornais apresentam a predisposição em pautar assuntos que simulem modernidade e sofisticação tecnológica. Em contrapartida, denunciam a decadência da qualidade de ensino e a precariedade das condições para o desenvolvimento de pesquisa no Brasil. 
Os jornais, comumente, associam o moderno como característico das sociedades altamente tecnologizadas, e o pré-civilizatório, arcaico e selvagem, acaba sendo projetado à imagem dos países do Terceiro Mundo. A ciência e a técnica, em si, são ideologias da lógica de sustentação do modelo capitalista de produção, que associa progresso técnico-científico à formação da civilização ocidental. $\mathrm{O}$ saber científico delimita as fronteiras do ingresso à modernidade.

A aquisição do supercomputador Gray-Y, pela Universidade Federal do Rio Grande do Sul, qualificado como "o rnais moderno e rápido da América do Sul", resolve em parte o complexo nacional de ficar à margem da modernidade. Como se depreende da reportagem "Pesquisa universitária é pouco usada", publicada no "Estado", a relação entre a universidade e o setor empresarial mereceria tratamento menos superficial.

Tidos como uma aproximação "natural", os jornais, normalmente, indicam os resultados em produtividade e lucros das empresas. A aproximação da universidade com o setor privado somente ocorre em algumas áreas de excelência (setores de informática, saúde e equipamentos de tecnologia de ponta), vinculadas ao crescimento do setor produtivo. Isto é visto como um aspecto positivo para o reaquecimento da economia nacional, sem maiores questionamentos das implicações desta relação entre pesquisa acadêmica e a demanda do setor empresarial.

A tendência da imprensa em utilizar o contraste para obter atenção, também pode ser notada no título de uma chamada do caderno "Cotidiano": "Cambridge acolhe 'geninho' rejeitado". No subtítulo, a "Folha" adjetiva que o "Brasil nega bolsa a economista prodígio". Trata-se do financiamento dado pelo governo britânico para Marcelo Tsuji, de 24 anos, fazer doutorado em Economia Matemática, na Universidade de Cambridge, após pedido rejeitado pela Fapesp.

$\mathrm{O}$ interessante nesta reportagem é a facilidade de adjetivações, preconceitos e afirmações definitivas, como: "Tsuji é um daqueles casos de quem não consegue se adaptar à ' lei do mínimo esforço' que domina a maioria das universidades brasileiras". Deslocada de uma discussão rnais 
ampla do ensino universitário brasileiro, esta opinião do repórter Fernando Rossetti sugere opinião automática, eivada desenso comum. Na reportagem interna, rnais exploração sensacionalista no título: "Marcelo 'devora' livros e evita namoradas".

A "Folha" foi "criativa" em substituir o essencial, que é a crise dos órgãos de fomento à pesquisa e sua relação com a estruturação dos cursos universitários, pelo insólito e caricatural. Ao invés de informações objetivas, o jornal salienta o autodidatismo do estudante "solitário" e elogia o seu ecletismo de comentar assuntos tão diversos como textos de Habermas, Nietszche e futebol. Se, eventualmente, não permitiu ao leitor esclarecimentos sobre a crise da pesquisa no Brasil, pelo menos publicou a opinião de Tsuji a respeito do provincianismo do paulistano e sua predileção futebolística pelo São Paulo Futebol Clube.

Com relação à política do governo para o ensino universitário, na posse do ministro da Educação, Murilo Hingel, o jornal "Estado" informou que, nos planos do novo governo Itamar Franco, as universidades iriam receber um "socorro financeiro" da ordem de Cr\$ 1 trilhão até o final de 1992. O jornal não esclarece para quais setores e planos esta verba seria alocada.

Durante o período de pesquisa, o governo anunciou a criação de cursos noturnos nas universidades federais. Entretanto, as implicações de natureza político-pedagógica não motivaram entrevistas com especialistas nem mesmo estatísticas da demanda de novos alunos. Neste caso, o jornal teria contribuído se problematizasse, por exemplo, as diferenças metodológico-didáticas, de qualidade de ensino, entre a universidade de tempo integral e os cursos para estudantes trabalhadores, à noite.

Se o interesse dos jornais pela educação não vai além da superiicialidade, da "semi-informação", para leitura e consumo rápido, justificamse os seus títulos impactuais, como: "Faap anuncia 'aluna-avião' em TV".

Este título da "Folha", a respeito da publicidade do vestibular da Fundação Armando Álvares Penteado, que relacionou suas alunas com "aviões", aponta para o crescente interesse dos mass media em se dirigir 
aos jovens através de programas de TV e cadernos especiais, diante da lógica mercadológica de segmentação de público.

A irreverência da campanha publicitária recebeu críticas da "Folha". Entretanto, o uso comercial da beleza feminina, no contexto da reportagem, despotencial iza a denúncia. Isto porque a "Folha" acaba confirmando a intenção da campanha ao publicar duas fotos editadas na reportagem em que aparecem uma loira e outra morena, confirmando as intenções da publicidade da escola.

Ao contrário de sua intenção, a "Folha" atenua o impacto desta mensagem machista e banaliza o preconceito quando registra expressões de alguns alunos, como: "o anúncio é legal", "gostei, legal".

Neste caso, esta realidade social que permite a mercantilização de vagas, como se fosse produto, acaba se tornando assunto de distensão através do humor. Horkheimer e Adorno (1990, p.182) observam que no contexto da indústria cultural "divertir-se significa estar de acordo". Estes autores frankfurtianos criticam a indústria cultural por tratar de forma banalizada assuntos sérios, objetivando exclusivamente entreter, sem se preocupar com "a onipresença do estereótipo" (id. ibid., p.174).

No período, foi publicado o protesto de alunos pós-graduandos por rnais verbas para a ciência e tecnologia. A "Folha" destacou a avaliação, entre 1970 a 1991, dos cursos de graduação da Unicamp, e também noticiou as atividades da 2- Semana Zumbi dos Palmares, promovida pelo Núcleo de Consciência Negra da USP.

As notícias do ensino universitário, de longe, permitem esclarecer a complexidade das diretrizes educacionais, da mesma maneira que os temas analisados sobre o $1^{\circ}$ e $2^{\circ}$ graus.

\section{Proposta de ensino}

Selecionamos algumas matérias que, sobretudo, acabam tendo uma importância para os profissionais da educação e cuja temática comumente fica ausente das páginas dos jornais: 
O "Estado", através da editoria de Educação ${ }^{6}$ publicou um artigo para enfocar novos métodos pedagógicos e, apesar do impacto do título "Técnica moderna pode aposentar a cartilha", o jornal deu espaço para se falar de recursos didáticos e de processo de ensino-aprendizagem baseado na psicolinguistica e na familiarização da criança com a escrita.

Os leitores da "Folha" leram as propostas educacionais dos "prefeituráveis" de São Paulo, no pleito de novembro de 1992. O jornal informou as principais mudanças ocorridas naquele ano sobre a organização do primeiro grau em ciclos, os critérios de avaliação, promoção e de reprovação. Especialistas analisaram a opinião dos candidatos Paulo Maluf (PDS), Eduardo Suplicy (PT), Aloysio Nunes (PMDB) e Fabio Feldmann (PSDB), a respeito do sistema de ciclos. A "Folha" dedicou uma página no caderno "Cotidiano".

A pesquisa do IBGE que "confirma (o) malogro do ensino público", publicada no "Estado", esclarece sobre o ensino no Brasil em relação à América Latina, fazendo paralelo com a recessão e a concentração de renda no continente. Ressalte-se que foi, no período de três meses, a única reportagem que relacionou o País com o contexto da América Latina, onde a realidade geopolítica, no caso específico da educação, é marcada por problemas estruturais de evasão escolar, analfabetismo e ausência de universalização do ensino básico.

A reportagem trouxe estatísticas da evasão escolar e compara o Brasil ao México, ao Uruguai e à Venezuela. As taxas de repetência e evasão são relacionadas com a pobreza, "agravada pela concentração de renda e pela desnutrição", e com o ingresso precoce de adolescentes e jovens no mercado de trabalho. O ensino público no Brasil e a escolarização das crianças são abordados de forma crítica e contextual izada.

${ }^{6} \mathrm{O}$ "Estado" mantinha no início dos anos 70 uma editoria própria para a educação, que atualmente se confunde com a editoria nacional, juntamente com ciência e tecnologia, saúde e meio ambiente. 
A multimídia ${ }^{l}$ aplicada à educação, as pesquisas desenvolvidas na USP sobre a "sala de aula futurista" ("Folha"), a distribuição de programas de microcomputador para a área educacional ("Estado"), muito em função do fascínio que provocam as novas tecnologias, recentemente têm despertado a criação de cadernos de informática e de reportagens especiais.

$\mathrm{O}$ uso do microcomputador, das novas tecnologias aplicadas à educação, na "Escola do Futuro", são vistos como aparatos capazes de revolucionar o ensino, reduzindo o processo de ensino-aprendizagem à condição técnica. A função do professor, neste caso, esgota-se na coordenação interativa dos alunos com as novas tecnologias e, magicamente, resolvem-se problemas da capacitação docente e dos currículos inadequados à realidade do aluno.

O "Estado" noticiou a inauguração da Escola "Jean Piaget", de Porto Alegre, como a "primeira escola construtivista do País". Apesar do apelo jornalístico expresso na adjetivação "primeira escola", e na qualificação da proposta construtivista como inovadora, a reportagem desperta interesse pela pesquisa e pela consulta. Entretanto, o jornal destacou em demasia o projeto arquitetônico e sua adequação às propostas construtivistas e pouco esclarece sobre a interação e a troca de experiências e vivências entre as crianças no processo de construção do conhecimento. Também deixa de abordar aspectos epistemológicos e sociolingüísticos do desenvolvimento da linguagem e das capacidades sensório-motoras da criança, e não fez uma análise histórico-cultural do construtivismo.

A mesma leitura se pode fazer da iniciativa da "Folha" ao anunciar a instalação de brinquedotecas em creches não-governamentais da periferia de São Paulo, apesar do título, "Primeiro Mundo cria brinquedoteca em São Paulo", que demonstra exagero. Numa entrevista à "Folha", com o título "MEC muda rumo e prioriza currículo", que denota o apego da

\footnotetext{
${ }^{7}$ Neste caso, o termo multimídia pode ser compreendido como equipamentos audiovisuais acoplados em computador. De maneira rnais ampla significa a concentração de meios de comunicação como, por exemplo, rádio, televisão e jornal, sob a mesma organização empresarial e concentrados num mesmo território.
} 
notícia à radicalidade de prescrever mudanças, o ministro Murilo Hingel pôde elucidar diretrizes governamentais sobre reajustes das escolas particulares, ensino universitário e qualidade de ensino, transcendendo a especulação da imprensa de se preocupar exclusivamente com orçamentos e despesas.

Outras reportagens apresentaram informações contextualizadas e críticas, como no "Balanço/Educação" da "Folha" sobre a gestão da prefeita do Partido dos Trabalhadores (PT), Luiza Erundina, em São Paulo. Do ponto de vista ideológico, no subtítulo o jornal é tendencioso ao afirmar que a mudança do sistema de séries e notas cria polêmica nas escolas. Entretanto, favoreceu a prática de se repensar a experiência.

Assim também a reportagem da "Folha" sobre "especialista (que) aponta erros de psicólogo escolar", ao trazer referências sobre o papel destes agentes educacionais. A reportagem criticou a "estigmatização das crianças, que surge com os estereótipos usados por psicólogos". A "Folha", com base em especialistas, disse que o psicólogo escolar deveria ter ação multidisciplinar rnais voltada para a aprendizagem e menos para os problemas clínicos individuais. O jornal acrescentou que a Psicologia Escolar da USP aboliu os chamados testes, inclusive para medir inteligência nas crianças, e reproduziu situações vivenciadas por esses profissionais.

A "Folha" também divulgou a pesquisa da USP sobre evasão escolar em seus cursos e uma reportagem sobre a relação entre o jogo e as operações matemáticas para crianças, no caderno de Informática.

\section{Editoriais}

O Novo Manual de Redação da Folha (1992, p.70-71) esclarece que o editorial expressa a opinião de um jornal, no qual são desenvolvidos argumentos e refutadas as opiniões opostas. Acrescenta que "os editoriais não dirigem o noticiário, mas temas que neles aparecem com frequiência devem ser explorados pela reportagem". 
Seguindo esta recomendação, os assuntos pautados nos editoriais se desdobram no corpo das reportagens. De maneira diretiva, os jornais indicam à sociedade quais os temas que merecem ser enfocados com destaque ${ }^{8}$.

Mesmo nos editoriais é sintomático o interesse pelo factual, ou seja, faz parte da natureza dos mass media, e no caso os jornais, selecionarem os acontecimentos noticiáveis em função do desequilíbrio que provocam na história cotidiana. Neste sentido, os editoriais refletem uma preocupação em dar opinião da direção sobre assuntos que emergem no calor dos acontecimentos diários.

Os editoriais sobre a participação e a mobilização estudantil, já no governo Itamar Franco, denominados "Democracia do Zé-Pereira" e "Rebelde sem Causa" ("Estado") manifestaram a preocupação dos jornais com a ação política dos caras-pintadas no processo de privatização. De maneira preconceituosa, como já analisamos no item "Mobilização estudantil pelo impeachment", os estudantes devem se preocupar com a sua formação e não com problemas da política nacional.

No item "Matérias publicadas na primeira página", dissemos que a compra inesperada de vagas na rede particular despertou interesse jornalístico. A "Folha" apoiou: "Esse tipo de terceirização da atividade do poder público representa uma opção que deveria ser seriamente considerada no Brasil". O jornal complementou que causaria rnais despesa a construção de novas escolas. Para a "Folha", a compra de vagas poderia, inclusive, representar "ganho de qualidade pedagógica".

Da mesma maneira, a deflagração de greves rompe a linearidade dos fatos. A paralisação dos professores e funcionários da PUC/SP mereceu do "Estado" editorial que abordou a crise da instituição e as conseqüên-

\footnotetext{
* Para evidenciar que a educação não desperta interesse jornalístico, basta enumerar que. nos três meses de pesquisa, ela foi objeto de opinião em apenas 13 editoriais, num espectro de 184 edições, incluindo a "Folha" e o "Estado". Isto equivale à baixa porcentagem de 2,1\%. A "Folha" publica três editoriais em média por dia e o "Estado", quatro. No período de $1^{\circ}$ de setembro a $1^{\circ}$ de dezembro, os dois jornais publicaram 664 editoriais. aproximadamente.
} 
cias da greve para os alunos, sem, entretanto, mencionar as cláusulas de negociações.

Nesta relação com o contingencial, pode-se incluir também o editorial publicado pelo Estado sobre "A novela das matrículas escolares". Durante o período de análise, houve muita controvérsia entre pais de alunos e escolas a respeito de pendências judiciais sobre mensalidades. Os leitores do "Estado", órgão que publicou o editorial, tinham interesse em acompanhar os desdobramentos, pois muitos mantêm seus filhos na rede privada. Já se falou no item "Reajustes das escolas particulares" que os jornais deixaram de enfocar a questão das mensalidades a partir da abordagem histórica, sem explicitar as contradições entre ensino público e ensino privado.

Do espectro reduzido de editoriais sobre educação, apenas algumas opiniões na "Folha" e no "Estado" escapam a essa necessidade de dar respostas aos acontecimentos cotidianos, no sentido de que problematizam questões estruturais, contraditando a busca do transitório, que pode transformar qualquer acontecimento insólito numa notícia.

Em editoriais também aparecem preconceitos, às vezes de maneira dissimulada. Quase sempre recai na formação do professor a precariedade do sistema de ensino, como se a culpa fosse meramente de seu desinteresse e falta de aptidão pessoal. Isto fica claro no editorial do "Estado" "O novo professor", quando reafirma o pensamento de Adorno (1992, p.76) sobre a desqualificação deste profissional como uma espécie de tabu.

Basta reproduzir a opinião de uma professora entrevistada pelo Instituto de Estudos Sociais e Econômicos (Inese), em cuja pesquisa o "Estado" se baseou para falar da desmotivação que cerca o trabalho no magistério: "Minha mãe tanto insistiu que decidi ser professora". A frase é paradigmática para demonstrar a representação inconsciente (Adorno fala em tabus) da aversão contra a docência, sobretudo em relação ao primeiro e segundo graus.

Este preconceito também se manifestou na "opinião do diretor de uma grande escola de São Paulo", que o "Estado" reproduziu no editorial 
"Data esquecida", quando opina: "Quem ainda opta pela docência tem falhas de formação". Mais uma vez o jornal aborda "a queda no salário e desprestígio crescente da profissão".

A questão do hábito de leitura no primeiro grau foi vista no editorial "Livro, criança e imagem". O "Estado", por sua vez, comentou a pesquisa da Fundação para o Desenvolvimento da Educação (FDE) São Paulo - , a respeito do livro infantil e do interesse das crianças pela leitura. Este jornal também opinou sobre as propostas de criação de "escolas-padrão", mostrando a expectativa dos professores em relação à capacitação profissional e à melhoria de salários. Entretanto, não questionou: a) os salários diferentes para a mesma função em escolas com o mesmo padrão; b) o preceito constitucional que impede diferenciar vencimentos da ativa e da inatividade.

A "Folha", no editorial "O tijolo ou o aluno?", discutiu os indicadores sociais do IBGE, que acusava que dos "59,7 milhões de crianças e adolescentes brasileiros, nada menos de 32 milhões estão excluídos da modernidade". Em seguida, criticou a liberação de verbas para a construção de escolas em municípios paulistas localizados em bases políticas de deputados federais, observando que os governos continuavam investindo "na construção de prédios, colocando em primeiro lugar o tijolo e depois o aluno".

Mais dois editoriais se destacam: "Sócio desinteressado", no qual o "Estado" abordou a relação entre universidade, projetos de pesquisa e meio empresarial, e "Equívoco corrigido", da "Folha", "que aprovou" a decisão do governo Itamar Franco de abandonar o programa dos CIACs.

Os editoriais também se basearam no factual e na omissão de informações, dando prioridade para política e economia. Do ponto de vista jornalístico, essas editorias se defrontam cotidianamente com polêmicas e situações imprevistas, sobretudo no Brasil, com permanente instabilidade nessas áreas. 


\section{Conclusão}

A "Folha" e O Estado de S. Paulo, mesmo que não sejam caracterizados como jornais sensacionalistas, apresentam na composição de títulos, na definição de pauta e nos critérios de construção da noticia, elementos de especulação do que possa ser representado como excêntrico, incomum.

Enfatizamos que esta prática se relaciona com o caráter mercadológico da notícia e que a editoria de educação não recebe o mesmo espaço e tratamento de assuntos cobertos pelas seções de economia, política ou esportes.

A racionalidade técnica aplicada à produção da notícia faz com que o processo de elaboração da mensagem seja padronizado e dirigido preferencialmente para determinados assuntos, sobretudo diante da obrigatoriedade intrínseca do jornalismo diário de fechar as edições em tempo cada vez rnais reduzido. O ritmo das rotativas dificulta se pensar a realidade em sua complexidade histórica. A transitoriedade dos fatos, pelo que provoca de reação direta, transforma o imediatamente dado num fenômeno, sem mediações e relação de causa.

Os jornais pouco contribuíram nas reportagens, editoriais, manchetes, artigos de "fundo", para aprofundar a discussão dos problemas nacionais de educação e das experiências de outros países com semelhanças geopolíticas, onde há os mesmos problemas de evasão, repetência e ausência de universalização do ensino básico.

A LDB foi praticamente esquecida. No caderno internacional, apenas assuntos sem relevância se transformaram em notícia. Durante a primeira etapa do processo de impeachment, a educação somente foi noticiada na primeira página com destaque quando o governo Itamar Franco decidiu comprar vagas nas escolas particulares. Novamente, o incomum foi critério de "noticiabilidade".

A partir do mesmo critério, também se inclui a greve de professores, pois promove um salto brusco na vida cotidiana e rompe a sequiência linear dos fatos. A polêmica move o jornalismo e desperta a leitura, a venda do jornal. 
Foi analisada a mobilização estudantil pelo impeachment e a ressignificação dada pela indùstria cultural aos movimentos populares e da sociedade civil, tendo subjacente a reafirmação ideológica do senso comum.

$\mathrm{O}$ trabalho tratou do interesse mercadológico dos jornais na criação de novos cadernos (dirigidos a jovens e adolescentes), para a formação de leitores e a ampliação da receita publicitária. Nestes cadernos segmentados, o jovem significa público leitor em potencial e se relaciona, do ponto de vista simbólico, com valores universais de beleza, jovialidade. Nota-se que, durante o período de impeachment do governo Collor, os caras-pintadas tiveram a sua imagem exaustivamente explorada em publicidades e propagandas institucionais. Com isto, procuramos demonstrar as relações conflituosas e tênues entre a linha editorial dos jornais e o espaço publicitário.

Analisamos o que foi relevante para a educação, no que diz respeito à política e aos planos/metas de ensino, do primário à universidade, e tratamos dos editoriais como rnais um dos gêneros jornalísticos que aponta para o descaso dos jornais em não atribuir à educação importância noticiosa.

Ressaltamos o caráter legitimador de instituições, personalidades e propostas, através da exposição nos mass media, como reafirmação de status, além de atentar para a ausência de informações e suas implicações ideológicas. Tal prática faz parte da natureza da comunicação mediática e de sua lógica de simplificação, omissão e tratamento parcial dos fatos sociais. Cabe à educação e a seus agentes construírem espaços de formação e de desvelamento da lógica dos mass media e ultrapassarem seu conteúdo, compreendendo sua natureza sistêmica.

\section{Referências bibliográficas}

ADORNO, Theodor W. A indústria cultural. Trad, de Amélia Cohn, 4.ed. In: COHN, Gabriel (Org.). Comunicação e indústria cultural. São Paulo: Ed. Nacional, 1978. 
ADORNO, Theodor W. Teoria da semicultura. In: RAMOS DE OLIVEIRA, Newton. Theodor W. Adorno: quatro textos clássicos (trad.). São Carlos, 1992, publicação interna.

. Tabus a respeito do professor. In: RAMOS DE OLIVEIRA, Newton. Theodor W. Adorno: quatro textos clássicos (trad.). São Carlos, 1992, publicação interna.

BOURDIEU, Pierre, O mercado de bens simbólicos. In: MICELI, Sergio (Org.).A economia das trocas simbólicas. São Paulo: Perspectiva, 1974.

BUFFA, Ester. Ideologias em conflito: escola pública e escola privada. São Paulo: Cortez e Moraes, 1979. (Coleção Universitária).

FREITAG, Bárbara. Escola, Estado e sociedade. 6.ed. São Paulo: Moraes, 1986.

. Política educacional e indústria cultural. São Paulo: Cortez, 1987. (Coleção Polêmicas do Nosso Tempo, 26).

Teoria crítica: ontem e hoje. 2.ed. São Paulo: Brasiliense, 1988.

GIROUX, Henry. Pedagogia radical. Trad, de Dogmar Zibas. São Paulo: Cortez, 1983. (Coleção Educação Contemporânea).

HABERMAS, Jürgen. Soberania popular como procedimento - um conceito normativo de espaço público.Novos Estudos Cebrap, n.26, mar. 1990.

HORKHEIMER, Max, ADORNO, Theodor W. A indústria cultural: o esclarecimento como mistificação das massas. Trad, de Guido Antonio de Almeida. In: Dialética do esclarecimento. 2.ed. Rio de Janeiro: Zahar, 1986. 
KANT, Imannuel. Resposta à pergunta Que é "Esclarecimento"? (Aufklârung). Trad, de Raimundo Vier e Floriano de Souza Fernandes. Petrópolis: Vozes, 1985.

KOTSCHO, Ricardo. A prática da reportagem. São Paulo: Ática, 1989.

LINS DA SILVA, Carlos Eduardo. Mil dias: os bastidores da revolução em um grande jornal. São Paulo: Trajetória Cultural, 1988.

MANUAL DE REDAÇÃO E ESTILO. Eduardo Martins (Org.). São Paulo: O Estado de S. Paulo, 1990.

MARCONDES FILHO, Ciro. O capital da notícia: jornalismo como produção social da segunda natureza. 2.ed. São Paulo: Ática, 1989.

MARCUSE, Herbert. Ideologia da sociedade industrial. Trad, de Giasone Rebuá. Rio de Janeiro: Zahar, 1967.

MARQUES DE MELO, José. Comunicação, opinião e desenvolvimento. Rio de Janeiro: Vozes, 1977.

MEDINA, Cremilda. Notícia: um produto à venda. 2.ed. São Paulo: Summus, 1978. (Novas Buscas em Comunicação).

MERTON, Robert K., LAZARSFELD, Paul F. Comunicação de massa, gosto popular e a organização da ação social. In: LIMA, Luiz Costa (Org.) Teoria da cultura de massa. São Paulo: Paz e Terra, 1990.

NOVO MANUAL DE REDAÇÃO. São Paulo: Folha de S. Paulo, 1992.

PENTEADO, Heloísa Dupas. Televisão e escola: conflito ou cooperação? São Paulo: Cortez, 1990.

PUCCI, Bruno. Teoria crítica e educação. São Carlos, 1993. publicação interna. 
RAMOS DE OLIVEIRA, Newton. Theodor W. Adorno: quatro textos clássicos (trad.). São Carlos, 1992. publicação interna.

WOLF, Mauro. Teorias da comunicação. 2.ed. Lisboa: Presença, 1992.

Recebido em 3 de abril de 1996.

Belarmino Cesar Guimarães da Costa, mestre em Educação pela Universidade Federal de São Carlos (UFSCar), é doutorando em História e Filosofia da Educação, na Universidade Metodista de Piracicaba (Unimep), na qual é professor e coordenador da habilitação Jornalismo do curso de Comunicação Social.

In industrial society, the mass media produce, exclude and modify aspects of reality. The criteria of newsworthiness used by newspapers are aligned with sensationalism, emphasizing facts that are shocking or extraordinary and which cause immediate reactions in readers. The production of news as merchandise is characterized by fragmentation and decontextualization. Education does not limit its action to the factual and, for this reason, does not acquire the status of news and is not questioned. This is evidenced by the news published in the newspapers "Folha de S. Paulo " and "O Estado de S. Paulo " with regard to the LDB (Lei de Diretrizes e Bases da Educação — general law regulating education in Brazil) which was being discussed and voted by the. National Congress during the impeachment of Collor de Mello, president at that time.

Dans la société industrielle, les mass media produisent, excluent et transforment des aspects de la réalité. Le principal critère de sélection des nouvelles par la presse est leur potenciel de causer des sensations, de produire de l'impact, de provocquer des réactions immédiates dans 
les récepteurs. La fragmentation et la descontextualisation sont les caractéristiques de la production de la nouvelle en tant que marchandise. L'éducation ne se prend pas au factuel et, de ce fait, elle n'acquiert pas le status de nouvelle, c'est-à-dire, elle laisse d'être potenciallement problematisée. Ceci s'est rendu évident pendant le processus de discussion de la LDB (Loi de l'Education National) e au Congrès Nationale et dans la publication de nouvelles au sujet de l'éducation dans les journaux Folha de S. Paulo et O Estado de S. Paulo, pendant le processus de l'impeachment du président Collorde Mello.

En la sociedad industrial, los mass media producen, excluyen y transforman aspectos de la realidad. Los criterios de noticiabilidade en los periódicos se pautan por el sensacionalismo, dando destaque a acontecimientos extraordinarios y de impacto que provoquen reacciones inmediatas en los receptores. La fragmentación de la producción de la noticia como mercancía. La educación no está fijada a lo factual y por eso no adquiere status de noticia y deja de ser potencialmente problematizada. Esto quedó evidente en los trámites de la LDB (Lei de Diretrizes e Bases) y en la publicación de noticias sobre educación en los periódicos "Folha de S. Paulo "y "O Estado de S. Paulo " durante el impeachment del gobierno Collor de Mello. 